University of Delaware Disaster Research Center

PRELIMINARY PAPER \#248

COMING TO TERMS WITH COMMUNITY DISASTER

Russell R. Dynes

1997 


\title{
COMING TO TERMS WITH COMMUNITY DISASTER
}

\author{
Russell R. Dynes Disaster Research \\ Center Department of Sociology/Criminal \\ Justice University of Delaware Newark, \\ Delaware, U.S.A. 19716
}

$\underline{\text { Abstract }}$

Concepts are most useful when their formulation leads to researchable questions. For social scientists, the concept of disaster need to be rooted in some social unit--the choice here is the community, a universal form of social life and response. Since disasters are normatively defined and are manifest by extraordinary effort on the part of community members, the most accurate indicators of disaster effects is found in the action and adaptation of community organizations. Two major community categories are identified--autonomous and dependentwhile two noncommunity types--sector and noninstitutionalized--are also suggested. These different categories lead to different research leads. In any case, disaster as social disruption has to be viewed in a social system context.

Disasters create many difficulties, even for social scientists. Social scientists have to deal with concepts that also have popular meaning and some of those meanings can carry with them high emotional content. When events invoke moral and emotional reactions, conceptual discussions about them can often evoke charges of moral insensitivity and professional arrogance. Too, interest in disasters cuts across disciplinary lines so one's own interest is given highest priority while the interests of others is considered marginal or perhaps even trivial. Given those difficulties, it is often prudent to ignore or at least to downplay conceptual discussions. 
Periodically, however, it can be important to raise such issues. One should, however, in the discussion about disaster, disclaim responsibility to catalogue every sin, every trauma, all evil that is intertwined with human history. There is a more delimited mandate to be explored here.

\section{Background}

As a preliminary step, it is not necessary to do an exhaustive history of the concept of disaster. Two sources will suffice for our more limited purpose. First is found in Organized Behavior in Disaster (Dynes, 1970) which was both a description of the early work of the Disaster Research Center and a review of prior disaster research. There, I note that there were four common usages of "disaster"--as agent description, as physical damage, as social disruption and as negative evaluation. That review noted that, in many discussions, different meanings could occur interchangeably within the same sentence but, for the purpose of DRC's research program, the most central meaning was social disruption.

While there have been periodic attempts to deal with the concept, a second source deals more directly with conceptualization. Quarantelli (1995) posed the question "What is a disaster?" to six researchers with different social science backgrounds. Their collective contributions were then critiqued and the authors were then able to respond. All of the authors focused in one way or another with the idea of disaster as social disruption. Gilbert (1995) emphasized disaster as the collapse of cultural protection. (I was also struck by Dombrowsky's use of the Promethean analogy to suggest that we often trim the solution to fit the problem, perhaps anticipating my discussion here.) Kreps' (1995) emphasis on disaster as a systemic event and as a social catalyst fits well with my own intellectual outlook. I found Porfiriev's (1995) extension of the concept to a social geographical area to be an interesting extension prompted by a set of pragmatic problems 
he confronted in his research efforts. Horlick-Jones' (1995) ideas of disaster as symbolic events pointing to the loss of control in the modern world fits well with the others. In spite of their differing national and disciplinary backgrounds, the authors seem to agree that disasters are "social" in origin; that agent determinism should be avoided; that social disruption should be the focus; that the concept is socially constructed and, to certain extent, there was agreement that the focus of research should be on the reacting and responding social organization. These agreements, however, provided ample targets for the reviewing critique.

In that critique, Hewitt (1995), after concentrating on selected aspects of the other papers, moved on to what he chose to call "exclusions" in the field--what the authors did not talk about. Gaps might have been a better descriptor since "exclusions" becomes pejorative. Hewitt suggests the authors are simultaneously theoretically naive and morally insensitive, since they did not attempt to account for either Hiroshima or Auschwitz. I would second the reaction of Dombrowsky (1995b) and the response of Kreps (1995b) to Hewitt's treatment of their discussions.

While disclaiming here the possibility of extending the concept of disaster to account all of the evil in the world, past and present, there still might be utility for the concept within the social sciences. Reference has already been made to the multiple meanings of the concept in Organized Behavior in Disaster. Other recollections from that source need to be made. The book was intended as first in a series of studies of the "various aspects of crises events." Its title was deliberately chosen" to counter the usual notion of disasters as being identified by the disorganization of behavior. The focus of the book centered on the ways organizations function in crises events. That focus was intended since, at that time, there was a corpus of research on disaster victims, but little on how forms of social organization dealt with disaster. In particular, 
DRC was interested in sudden impact events which would provide the maximum conditions for understanding the functioning of social systems. This emphasis on organizations in sudden onset events led to a primary concern for the emergency period and subsequently has been the base for an argument that this stream of research was insensitive to "victims" and to slow onset events. The book, however, pointed out that "While large scale community disasters provide a kin of maximum test of organizational functioning, other lesser crises and stress situations can also provide the opportunity to obtain useful and basic theoretical knowledge about the operation of social systems." (1970, p. 4)

In any case, the book recorded the evolution of a series of decisions which guided DRC research, rather than a comprehensive attempt to "define" disaster. At that time, we were interested in "disastrous' events as a source of organizational stress, since these events had the effect of increasing organizational demands and decreasing organizational capabilities. This dialectic of a demand/capability ratio was a useful heuristic tool to think about the social consequences of disasters. While that approach was more fully explicated in Complex Organizations: A Sociological Perspective (Haas and Drabek, 1973, Chap. 7), it never served as a major point of departure for organizational theory or disaster research. The lessons derived from that experience was that for social scientists to study disasters, one had to start with a particular social location--a social unit. This identification of the social unit meant that familiar processes could be utilized as explanatory variables. Too, existing theoretical schemes and methodological approaches could also be utilized. In other words, while the events might be extraordinary, the research approaches necessary would be usual and ordinary.

On the Meaning of Social Disruption 
The notion of social disruption, as disaster, is more difficult. The traditional solution to this problem has been to infer social disruption directly from physical damage. The general logic is that the higher the number dead, injured and the greater the property damage, the greater the social disruption. This logic has considerable appeal, especially when the physical sciences and engineering disciplines use quantitative measures to indicate physical disruption. Eight points on the Richter scale is worse than six or seven. Two hundred mile winds in a hurricane is worse than 100 mile an hour winds. And 100 dead is worse than ten dead.

In multiple measures, however, you have considerable problems with combination. Is ten deaths worth 100 injured or worth $\$ 1,000,000$ in property damage? Obviously such measures have to be evaluated in a specific social context. Ten dead in a community of 200 is more disruptive than in a community of one million. A million dollar property damage to one family is different that that aggregate sum is in a community of 10,000. Also, the death of an 80 year old is less likely to be socially disruptive than someone at 30 . So, not all deaths can count as one.

One possible solution to the multiple measures is to talk about thresholds. Kreps (1995a) alludes to this issue in his recent review. If one establishes levels of damage and when these levels are exceeded, then by definition, a disaster has occurred. While this has the appeal of some standardization, such thresholds are of little value for comparative studies in different social systems and economic thresholds quickly become eroded by inflation. More importantly, the mental gymnastics required to move from physical damage to social disruption are of Olympian proportion. It is easy to argue that governments should collect "real" social indicators of disruption, but it is unlikely that such an innovation will become a reality. The collection of social statistics is based on the identification of stable social characteristics and administrative units are never coterminous with an impact zone. Too, post impact collection of social disruption data 
would take time. While this might reassure some of conceptual comparability, it is not likely to convince those who have experienced the disaster of the validity of those retrospective measures. While we wait for improved measures of social disruption and its speedy collection post event which would lead us closer to conceptual nirvana, we need to find other ways to entertain ourselves. If you are going to study disaster as social disruption, you need first to identify the social unit. That means that you are going to have to develop more reliable social/behavioral measures, not measures of physical damage which guarantees pov-hoc explanations. If one shifts from aggregate indices of harm to focus on measures of non-traditional efforts of those in the social unit, then "disaster" will make more sociological sense. It should be clear that this approach is not intended to explain unique events in human history, such as Hiroshima or Auschwitz, but only those repetitive experiences in human communities in different social and cultural contexts. We move then to a more sociological view of disaster and to indicate areas of research which emerge from that conceptualization.

\section{$\underline{\text { Toward a Sociological Conceptualization of Disaster }}$}

Let us start with an initial conceptualization which has considerable value for the following reasons.

1. It is based on a social unit.

2. It is based on a social unit which has cross national and cross cultural applicability.

3. It is a social unit that has the capacity and resources to activate a response to the disaster.

The particular social unit--the community--is a universal focus of social activity. Every community occupies physical space and has, in most cases, territorial boundaries so that the social 
entity can be characterized in part by its terrain and climate conditions. Communities have names and some degree of permanent settlement. But these physical, legal and material features are only one dimension since communities are very complex systems of human activity. It is useful to think of a community as a structure which has evolved to meet needs and to deal with problems as well as to allocate resources to problems. This allocation process takes place within an organized division of labor as groups and organizations engage in efforts relating to one or more community need. Thus, the community has to be conceptualized as a multi organizational system. In this conceptualization, the location of social action is the community.

So with the focus on the community, it is clear that disaster is "defined" in the emergency period. As we have already suggested, disaster "agents" are not self evident. History is replete with examples of how communities are able to justify effects by religious and political ideology. This underscores the notion that disasters are socially constructed. (For an excellent treatment of the social construction of earthquake threat at the national level, see Stallings 1995.) The following formulation would seem to capture the relativity of the concept.

A DISASTER IS A NORMATIVELY DEFINED OCCASION IN A COMMUNITY WHEN EXTRAORDINARY EFFORTS ARE TAKEN TO PROTECT AND BENEFIT SOME SOCIAL RESOURCE WHOSE EXISTENCE IS PERCEIVED AS THREATENED.

There are several implications of that type of formulation. It is usual to talk about disaster agents creating disaster events. Here there is no reference to disaster agents which implies that all disasters are socially caused. Specific names or traditional distinctions—God/Man, Natural/Technological--are less statement of causation than they are remnants of yesterday's normative arguments. Also, yesterday's inattention may be tomorrow's disaster and a disaster in 
one socio-cultural system may not be in another. In addition, for the term event, it is better to substitute "occasion." Event can imply a determinism which is not intended, a predetermined outcome. Occasion suggests more effectively the notion of an opportunity for something to happen.

The next question centers on identifying the norms of definition and the sources of definition of social harm. Quarantelli (1985) has suggested a number of dimensions which may be central to evaluating social harm. These would include the proportion of the population in a community which are involved, the social centrality of the involved population, the length of involvement, the rapidity and predictability of involvement, the unfamiliarity of the crises, the depth of involvement and possible recurrence. This would suggest that occasions would be defined as disasters where there was extensive damage to community resources and to the health and social status of those who are central to the life of that community (e.g., community leaders) and to those who are dependent on those community resources (e.g., children, older persons, the injured and infirm.) If such communities were involved rapidly and unpredictably and if that involvement were expected to continue and perhaps to recur, it would be quite likely that such occasions would be defined as disasters. The issue is more complicated, however, in the contemporary world. Rather than the evaluation process being limited to community residents and perhaps to political leaders who have interest and responsibility, in the contemporary world, the important mediating element in the evaluation process is the "media." Implicitly, one of its major functions has been to define "disasters." While much of the research on the media in disasters has focused on the accuracy of the coverage, that emphasis perhaps misses the point. It may be more important to view media coverage in terms of transmitting symbols which prompt concern and stimulate citizen involvement. The fact of the persistence of disaster myths in media 
coverage suggest that the themes drawn from normative criteria--on damage, on populations that need protection, on the interruption of hope--play an important role in defining the situation for others.

However, focusing on normative criteria, embedded in public opinion and in media coverage explains only part of the definitional process. Values need to be embedded in concrete social structures to influence action and activities. While one of the characteristics of the emergency period is the search for information, most of the "factual" information is not known until much later in the social process. In effect, response precedes the compilation of accurate information. This suggests that changes in behavior and social structure make a more accurate measure of "damage" than to the conventional physical measures. Suggestions for the measurement of those changes follow.

\section{Organizational Involvement as the Key Determinant}

Analytically, the effort should be directed toward identifying behavior which reflects "extraordinary effort. "That is, elements which have their roots in the pre-disaster community but which are refashioned. Several possible indicators are suggested. One would be the involvement of community members in behavior which is not mandated by pre-disaster roles. These are usually considered "volunteers" who participate in ephemeral roles (Zurcher, 1968). While the participation of volunteers has long been observed in disaster research, it is seldom studied directly. There is scattered research which provide insight into rates and patterns of involvement. (For a more extended treatment, see Dynes, 1994.)

Probably the most important summary measure of a community's extraordinary effort is reflected is what has come to be known as the DRC typology (see Figure 1) which conceptualizes 
the involvement of community organizations in disaster tasks and looks at the relationship of pre disaster tasks and structure to post "impact" involvement. Type I organizations carry on the same tasks with the same structure but often expand their conventional efforts by extending the work day and double shifting. Type II organizations expand their structures to carry out anticipated disaster tasks. These organizations anticipate the involvement and use of volunteers and thus expand to cope with the extraordinary effort. Type III organizations had no anticipated emergency responsibility but may become involved once they possess manpower and other resources. This might describe construction companies that become involved in debris clearance or even search and rescue. Type IV organizations have no pre-disaster existence but become involved with new tasks and develop a structure to deal with those tasks.

The purpose of introducing the typology here is to suggest that the pattern of organizational involvement is the best indicator of extraordinary effort and a behavioral reflection of normative judgments in defining a disaster. Put as a more circular way, when emergency organizations become involved, it is defined as an emergency. Organizational action implies that normative criteria are being evoked. This behavioral indicator is a much more concrete evidence of the definition of disaster than abstract "public" opinion or retrospective assessment of physical damage.

While there have been several extensions and refinements of the typology (Stallings, 1978; Brouilette and Quarantelli, 1971; Bardo, 1978; Forrest, 1978; Drabek, 1987; Dynes and Quarantelli, 1980; Weller and Quarantelli, 1973), it is useful to note here the work of Gary Kreps and his colleagues (Kreps, 1989; Kreps and Bosworth, 1993). In exploring patterns of stability and change of disaster involvement, Kreps merged organizational and collective behavior perspectives and makes a distinction of four structural elements which are individually necessary 
and collectively sufficient for organization to exist. From four structural elements--domains, tasks, resources and activities--Kreps develops a taxonomy of 64 structural forms. Starting with the pattern of D-T-R-A or formal organizing at one end (Established Organizations in the DRC typology) and A-R- T -D or collective behavior at the other end (Emergent Organization in the DRC typology). While allowing an analysis of greater complexity, Kreps' work provides support for both the existence of and the importance of the four fold typology. For the purposes here of developing a taxonomy of community disasters, the four fold typology will be sufficient to serve as the basis for the exploration of different types of community disasters. The purpose of the following distinctions is to point to different research questions central to different types. In addition, since "community" is a universal social unit, the discussion attempts to make the various types relevant cross-culturally.

\section{$\underline{\text { Categories of Community Disasters }}$}

From the viewpoint of the community system, it is possible to identify several model types of disaster. The first type and the "basic" model is called the Autonomous Community Disaster. This type would fit many disasters in developed countries. The community system is the location of the "impact" and the response by local community organizations. That involvement reflects a consensus that an extraordinary efforts are being undertaken to deal with the social resources which are being threatened. An important sub-type of Autonomous Community Disasters is what will be called Community Accident. The difference implied here is that the response is focused on the activities of institutionalized emergency (Type I) organizations. In effect, it is a delimited disaster and better characterized in "accident" terms.

The second major type is what will be called Dependent Community Disasters which 
implies that additional response resources are provided by other social systems, external to the community. Three sub types are identified: (1) Conflict Dependent,(2) Client Dependent, and (3) Proxy Dependent. These are all situations in which the local community is seen as dependent by external agencies, both national and international, that can become involved. This in effect creates a "dual" system, which creates an emergent pattern of organizational involvement.

There is a final category added for completeness and that is what will be called non community disasters. The first sub type is called here a sector/network disaster and the final subtype is labeled a non-institutionalized disaster, which represents an oxymoron. In effect, these two sub types represent conditions where there is limited "consensus" on social harm as well as limited institutionalization within community organizations about the nature and propriety of involvement (see Figure 2).

The rationale for the development of different disaster types is not to create meaningless and academic distinctions but as a basis for illustrating important similarities and differences among types. One of the persistent problems of the interpretation of research has been that "conclusions" are drawn based on one disaster type and then generalized to other quite different types. The rationale here for the taxonomy is to point to different research questions.

The major difference among the types is centered in the notion of the capability of communities to respond on the basis of their own social resources. Resources here are conceptualized in terms of the organizational structure of the community. I am assuming that there will also be considerable complexity of informal activity. This Barton (1969) has called the mass assault, that is "helping" activity on the part of persons, small informal groups and families which would constitute an important part of the total community response. The more formally organized structures of the community, however, constituted the core of the organized response. 


\section{$\underline{\text { Autonomous Community Disasters }}$}

Two sub types are differentiated: (1) community accidents and (2) community disasters.

(1) Community Accidents. These are situations in which an occasion can be handled by Type I or emergency organizations. The demands which are made on the community are within the scope of domain responsibility of the usual emergency organizations--police, fire, medical and health personnel. Such accidents create needs (and damage) which is limited to the accident scene so few other community facilities are damaged. Thus, the emergency response is delimited in both location and to the range of emergency activities. The primary burden of emergency response falls on those organizations which incorporate clearly deferred emergency responsibility into their domains. When the emergency tasks are completed, there are few vestiges of the "accident" or lasting effects on the community structure.

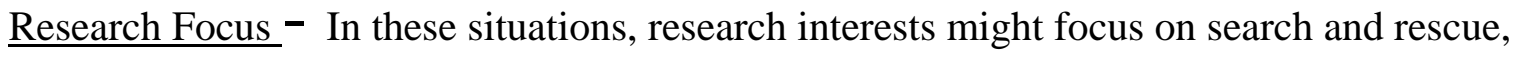
delivery of emergency medical services, security at the disaster site, coordination of multiple emergencies, handling of temporary interruption of community services, etc. Another focus could be on the "first responder," on the implementation of mutual aid pacts, the emergency of patterns of coordination, study of convergence on accident site, social control of convergence.

(2) Community Disasters. This type represents the more traditional disaster. Differentiating this type from a community accident is the extensiveness of involvement of organizations and other segments within the community. In community accidents, the emergency organizations will have developed some familiarity and accommodation to the domain definitions of other Type I organizations. In a community disaster, the pattern of damage may extend to several different places in the community rather than being focalized as it is within a community accident. Too, a number of community structures, perhaps including those which might house the 
traditional emergency organizations, might be damaged or destroyed. To determine whether such conditions exist requires the collection of information--from other organizations. The increased involvement of other "non-emergency" organizations then creates the need for coordination of activity and for new patterns of communication among parts of the community that previously had no reason to communicate.

The need for coordination and the development of new forms and channels of communication have been termed "response generated" demands as opposed to "agent generated" demands. In other words, they are demands which arise because of the response itself and not because of the agent. (This distinction, however, is frequently overlooked during the emergency and is often ignored in disaster planning which assumed that the demands being made on the community organizations derive from the disaster agent itself The combination of agent generated demands and response-generated demands creates a new and generally unfamiliar complexity to social relationships within the community.)

In terms of the previous comments about slow and gradual onset disasters, a sudden onset disaster would involve Type I and II organizations in rapid mobilization, quickly followed by Type III organizations and the rapid emergency of Type IV while gradual onset would involve a more deliberate sequential pattern of I, then II, then III and perhaps then IV organizations.

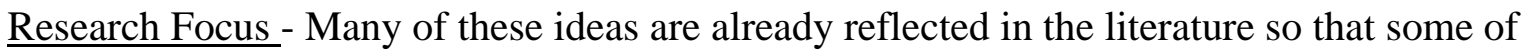
the research focus would be on the elaboration and replication of those notions; the time phasing of organizational involvement has not to my knowledge been studied directly; much more needs to be done on response generated demands. This category would encompass most disaster cases occurring in urban areas in developed countries and perhaps in most developing countries. It is important to note that the same "agent," such as cyclones, might create several different disaster 
types within communities which are in close geographical proximity.

\section{Dependent Community Disasters}

In certain ways, these disaster types are extensions of the previous type, except that the local community response is compounded by outside assistance. This perhaps implies that, in such situations, the capacity of a community is "weak," incapable or perhaps even non-existent. That may be the case, but in actual experience it would seem that higher levels of government as well as other extra-community non-governmental agencies make a "prior" determination within their domains to provide "assistance." That definition of "obligation" overrides and precludes determination of need. There may be examples of where community organizations are overwhelmed but nearly that assessment is made by organizations external to the community as a matter of course in justifying its involvement. Such external involvement, of course, may be "requested" by local officials, at times perhaps by uninformed and inexperienced officials. In any case, the differentiation of this type from the previous type is marked by extensive organizational involvement by extra community organizations.

Three different dependent community disasters can be identified. In all of the sub types, the assumption is made by organizations external to the community that the local response capacity is weak, damaged or non-existent. The three sub types are: (1) Conflict Dependent, (2)

Client Dependent, and (3) Proxy Dependent.

(1) Conflict Dependent. Perhaps a better term would be "violent" conflict or the concept of civil "strife. " Certainly, conflict is a common feature of every community. However, conflict usually operates within a context of some normative limits, e.g., within the "governmental process." There are many occasions when violence, or force or threat of force is used as a 
method of conflict directed toward some political end. This is an area of many complex issues in conceptualization which will be slighted here but the simple observation will be made that aspects of violence often become institutionalized to the extent that units external to the community see themselves as "necessary" to support the local "deteriorating" and perhaps polarized community organizations. Such external interests may serve to strengthen perceptions of unfairness and can lead to further divisiveness. Increasing divisiveness is then seen as justification for additional external assistance. The pattern of organizational involvement is, by its very nature, "emergent" and a frequent outcome is the creation of a dual assistance system, somewhat isolated from one another and at times "opposed" to one another.

(2) Client Dependent. A rather common pattern of disasters, especially in developing countries, are what can be called client dependent disaster. The assumption is made that the local community is unable or incapable of dealing with the range of disaster demands. Thus, high levels of government assumes that such communities have to be supplemented or "strengthened." In certain instances, this assistance could be the result of disaster preplanning but in most cases, the judgment is made case by case, so that the pattern of organizational involvement is almost always emergent.

(3) Proxy Community. These disasters are defined most frequently by media, national and international organizations relating to gradual and perhaps chronic demands which over time are assumed to have lowered the capacity of community systems to act as a responding unit. To a large extent, the "response" community are "surrogate" composed of fragments of previous social structures. Those fragments may come from the consequences of other disasters when in response smaller social units, such as families, have migrated. The interest here, however, is not on tracing the complex casual links but on the notion that, at some point in time, a "catchment" 
area develops and is identified as containing aggregates of people who have been earlier "disenfranchised," i.e., hold citizenship in no viable community. These circumstances result in the creation of an "ad hoc" community or "surrogate" community, an amalgam of many local, national and international elements of social structure which cumulate. That process creates a new "community" with the primary function of responding to immediate disaster needs as well as to develop longer term "solutions," perhaps the re-establishment of some "real" community.

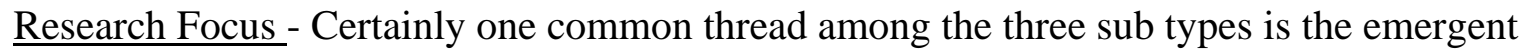
system which characterizes the disaster response, in large part because prior disaster planning is likely possible only by external agencies, consequently, the pattern of response then centers around the needs of the external agencies, rather than the clients. In effect, the emergent systems are likely to be rather paternalistic. Perhaps instances which do not fit the pattern of paternalism should be especially sought out to study.

In conflict dependent, the dual system might best be studied from the viewpoint of the community conflict literature and in terms of political and social movements. There is some literature of the differences in the functioning of emergency organizations conflict and consensus disasters. There is also some literature of the differences in the functioning of emergency organization in conflict and consensus disasters. There is also some literature on forms of "deviant" behavior in the contrasting situations as well as the emergency of new "accommodating" leadership roles. Not a great deal is known of the longer term consequences of community violence and the adaptation which family units make to that, although considerable insight might be derived from "wartime" situations.

In the proxy community, a research focus could be directed toward the continuities of social life which persist among the "victim" population(s), continued patterns of migration, the 
reinfranchisement process, the integration of local and external elements in the social "construction" of the community, differential patterns of response by different international agencies and by differing organizational philosophies, the shifting pattern of community needs in relationship to external political considerations, etc.

It would seem to be that most "famine, “ drought, and perhaps refugee situations should be studied from the viewpoint of the "proxy dependent" community, at other times as client dependent and perhaps on occasion as autonomous community disasters. There is no reason to assume that they should be any different than any other "agent" in having differential effects. It is quite possible that a more detailed typology of proxy community could be developed by examining "case" studies. Such research might result in more complexity or perhaps the category does not reflect a core of reality. There is some literature on the creation of "intentional" communities and there is also a scattered literature on relocation and resettlement which provide certain hypotheses.

\section{$\underline{\text { Non-Community Disasters }}$}

There are two other disaster "types” which will be mentioned here for completeness, although they may not merit extensive attention at this time. The differentiation important here is that the central analytical social unit is not the community. In these types, "impacts and the response isfocused on other social locations. The primary example will be identified here as the sector/network "disaster."

Sector/Network "Disaster." This type is best explained by contrasts to the previous discussion. In contrast with community disasters, demands are primarily confined to one sector 
(institutional area) of the community and thus have little significance for the broad range of potential emergency organizations. That is, the effects do not directly affect normative domains of many other organizations. Thus, the "disaster" is a sector "problem" rather than a "community" problem. The response structure does not take the usual community format but is sectorial, linking a network of people and organizations together but that response does not demand extensive or total involvement of most community emergency organizations.

It would seem that most current environmental issues are best described as sector disasters, as well as responses to most disease entities. It is also important to note that there are parallel sub types in reference to sector accident, which would now describe most incidents of hazardous materials spills in developed countries. In addition, there are examples of what might be called dependent sector disasters, which now characterize many of the environmental ecological issues in developing countries. The network within the sector links persons and organizations within the local community with others at the national and sometimes the international level. Those linkages often create the opportunities for potential conflict when national and international members of the network demand greater local concern and involvement than the "locals" feel is merited.

Research on sectorial disasters would substitute a social network focus for research, rather than a community focus. In addition, the perception of community members as to the obviousness and seriousness of demands would be researchable. One might hypothesize that most community members would reflect rather little normative concern. Consequently the network might attempt to create a heightened awareness of the disaster demands and their consequences. The vocabulary they use to define the problem may be apocalyptic and epidemic. In these types of disaster, the media might play important "defining" roles. In fact, one of the strategic direction of 
sector networks would be to convince other sectors in the community that sector disaster is actually "community" disaster. That status might describe Love Canal in relation to toxic materials as well as San Francisco in reference to AIDS. Careful research on the expansion of sector disasters to community disasters might provide one research focus.

Non-Institutionalized Disaster. The final "type" is a contradiction in terms of the theoretical scheme just presented so an accurate label is difficult to find to convey empirical reality. Perhaps the terms of "near-disaster," "public opinion disaster," "movement disaster," or perhaps "non-disaster" might describe certain cases which are at the margins of consideration, especially when the term has been defined here in terms of the institutionalization and involvement of emergency organizations. Its very description of not being well institutionalized within organizations could preclude its consideration within the typology. There are periods of when "potential" demands become a part of public discourse. That discussion centers on "shifting" what previously have been considered "personal" problems to the level of concern which deserves institutionalized attention within the community. Such public discussion centers on the criteria of social harm, the capability of the victims, their characteristics and the scope of social responsibility. That is, there are discussions about effects, about victims and social responsibility.

These issues are not only the focus of media attention but can be a focal point in the development of social movements and political protests. It is quite possible that these "non institutionalized" disasters are simply an early developmental stage of sector or community disaster. It may be the identification of social harm, particularly among innocent victims, is a necessary precondition to the discussion of the location of social responsibility. Too, the focus of social responsibility may shift from "private" to governmental organizations in that developmental process. While this is not the place to further explore these issues, they should offer many research 
opportunities. The issues, however, are more likely to utilize theories of mass communication, collective behavior and social movements than organizational and community theory. A careful examination of historical materials might reveal a "stage" theory of disaster more clearly linked with their "origins" in social movements, rather than linked to physical conditions.

\section{$\underline{\text { Other Considerations }}$}

While the previous discussion has focused on the community as a key analytical unit, there are obviously other choices, other social units--the family, task sub systems such as search and rescue, political and administrative systems as well as regional, national and international systems. Wherever the starting point, it is important to keep system inter-relationships at the core of research. Nowhere is this more important when the focus is on individuals. Individual responses always have to be interpreted in some social context, not as some inherent personality trait or as some inferred cultural trait, such as fatalism. As a general principal, behavior at lower level systems can seldom be explained without understanding the social context in which that individual operates.

Too, while the previous discussion has focused on social structure, that focus centered on a specific time phase of the disaster occasion--the emergency period. By implication, that formulation implies the possibility of viewing the disaster occasion along some continuum of social time. In general, a common vocabulary has emerged which includes mitigation, preparedness, emergency response, and recovery. Those stages should not be measured in chronological time but as a characterization of activities and processes. The various stages are intended to exhibit continuity and are, in effect, circular in nature. I would argue, however, that the emergency response phase is most important in understanding the entire process, since the 
combination of pre-existing community organizations and emergent behavior are the critical elements which affect subsequent phases of the process.

Of course, there are other conceptual possibilities which allow certain topics to be understood with some degree of completeness. For example, it is useful to take a social systems approach in the considerations of topics, such as warning, since that process involves action by organizations that monitor threats transferring information to organizations that prepare warning messages which communicate those messages to various "populations." Those populations interpret those messages in differential ways which evokes several forms of social interactions and ultimately, a range of behavioral responses. This complex social process involves several stages as well as several different levels of social structure. It can best be treated as a middle range theory so that incomplete knowledge can more easily be identified. There could be other "middle" range theories centering in such concepts as evacuation, relocation, mass assault convergence, organizational change, interorganizational coordination and long term community change.

Finally, there are always opportunities in disaster occasions to test theories and concepts derived from completely different contexts. For example, when the Disaster Research Center started organizational research, the initial models, drawn from the existing organizational literature, were found to be too static to deal with organizational behavior in disaster. Consequently, this led to the development of other conceptualizations, such as the typology of organizational involvement introduced earlier.

If more general theory has validity, then it should have validity in the disaster occasion. For example, family decision theory should work in the decision to evacuate and/or family adjustment theory should be applicable in understanding the recovery process at the family level. The point is that good theories of behavior should be applicable in disasters. If they are not, then 
combination of pre-existing community organizations and emergent behavior are the critical elements which affect subsequent phases of the process.

Of course, there are other conceptual possibilities which allow certain topics to be understood with some degree of completeness. For example, it is useful to take a social systems approach in the considerations of topics, such as warning, since that process involves action by organizations that monitor threats transferring information to organizations that prepare warning messages which communicate those messages to various "populations." Those populations interpret those messages in differential ways which evokes several forms of social interactions and ultimately, a range of behavioral responses. This complex social process involves several stages as well as several different levels of social structure. It can best be treated as a middle range theory so that incomplete knowledge can more easily be identified. There could be other "middle" range theories centering in such concepts as evacuation, relocation, mass assault convergence, organizational change, interorganizational coordination and long term community change.

Finally, there are always opportunities in disaster occasions to test theories and concepts derived from completely different contexts. For example, when the Disaster Research Center started organizational research, the initial models, drawn from the existing organizational literature, were found to be too static to deal with organizational behavior in disaster. Consequently, this led to the development of other conceptualizations, such as the typology of organizational involvement introduced earlier.

If more general theory has validity, then it should have validity in the disaster occasion. For example, family decision theory should work in the decision to evacuate and/or family adjustment theory should be applicable in understanding the recovery process at the family level. The point is that good theories of behavior should be applicable in disasters. If they are not, then 
they are not good theories.

\section{$\underline{\text { Conclusion }}$}

It is necessary to conclude even when concepts are obviously open-ended. For this sociologist, disaster means observing the disruption of some social unit. One conceptualization of the disaster occasion was presented based on the idea that disasters are always normatively defined. The focus of such definitions has been the community since that form of social life is always the primary responding unit. The indicator of extraordinary effort was organizational involvement, since disaster demands have to be related to the community's organizational capabilities. Two major disaster occasions--Autonomous Community and Dependent Community--and two noncommunity based types--sector-network and "non-institutionalized" disasters--have an identifiable base in the organizational structure of the community. Possible research leads are offered for the different types. Alternative conceptions of disaster occasions can also be based on social processes, systems theories and also can be used to test more general theories within the social and behavioral sciences. 


\section{On the Concept of Disaster: A Response, A Slight Recovery and Less Reconstruction \\ Russell R Dynes, Disaster Research Center, University of Delaware, Newark, DE, U.S.A.}

My primary response to Ronald Perry's comments is appreciative for his effort, integrating diverse visions of disaster. Two of the comments he made about my paper can be noted with agreement. He suggests that the typology of disaster which I developed based on the "community" might be better framed in terms of "social systems." I agree but I chose "community" as a more pragmatic referent for the more abstract "social system." In retrospect, "community" is also abstract so my initial decision was not particularly helpful.

Perry also suggested that the concept "disaster" might better be nested in a larger category of "collective stress." I have always admired Alan Barton's creativity and audacity in developing, in the late 60 's, that classification system which attempt to bring disaster into a more inclusive typology reflecting types of social impact. Barton argued that collective stress occurs "when members of a social system fail to receive expected conditions of life from the system." That has a nice ring to it until we try to imagine what that might mean and how we might develop indicators for stress. What are "expected conditions of life?"

Posed in that way, there are implicit notions of how social systems are supposed to perform (reminiscent of functional prerequisites within Parsonian structure functionalism, popular at the time when Barton wrote) and there are echoes of some base line of psychological well being. Are people supposed to have predictability and stability in life, the lack of pain and injury, the absence of fear and anxiety and the assurance of the fulfillment of aspirations and expectations? If so, disaster mitigation would only require reduced expectations. Defined in those terms, collective stress is 11 constant condition of routine social life. 
Barton rather creatively took three dimensions of disaster agents--scope of impact, speed on onset and duration of impact--as causes of collective stress and suggested that such stress involved unfavorable changes in the external environment as well as internal-social disorganization. Again, this has considerable face validity but it does not directly address indicators of collective stress. Unless we make progress in defining that, we will continue to use imperfect surrogates. The fact that the research field has not moved very far in that direction points to our own lack of sociological imagination as well as the persistent difficulty in developing measures which are not individually and psychologically based. This is why I tried to use organizational involvement as the primary base for the development of my typology. Indications of "extraordinary effort" attempts to point to behavioral indicators which could differentiate disaster behavior from "normal, routine" behavior.

After framing the original paper, there was still time to recover and to consider my initial effort and its shortcomings. Some of those afterthoughts might be relevant here. In some instances, conceptual analysis can be illuminating but it also can be paralyzing. Conventional wisdom emphasizes that adequate theory should proceed research but never what should precede theory. Such preoccupations often prevents us from raising realistic empirical questions. One of my colleagues spent his entire career trying to conceptualize a particular segment of his field. When he finished, his solution was passé and so was he.

Conceptual analysis is especially difficult when dealing with popular and commonplace terms. Attempts to gain precision seems pretentious to others. In addition, it is not necessarily true that conceptual consensus will lead to an explosion of productive research. More likely to spur disaster research would be an increase in research funding, produced by media and political attention. 
Taxonomic approaches always produce residual categories. The further elaboration of taxonomies to clarify those "contaminated categories" usually leads to cells, empty of content. So, increased clarity can lead to decreased significance.

Many putative theoretical breakthroughs in disaster research are based on what I would call" agent exceptionalism." In these instances, researchers suggest that "their" disaster is different--bigger, more important, more significant, more traumatic--than those others have studied. Such claims are usually true by assertion. If you define disaster by qualities of agents, different agents produce different disasters. While we need to appreciate that some writing and research careers are built on making tautalogical differentiations, in the long run, such claims add little to our collective understanding.

It is not likely that we will make significant progress until we have developed some sociological measures of social impact/social stress. My suggestion of "extraordinary effort on the part of community organizations' might be a start since it gets away from agent characteristics. I would infer from Perry's comments that Stallings suggestion of "disruption of routines" points to a similar direction. Unless we develop independent measures of "social" impact, the concept will remain the functional equivalent of post-traumatic stress syndrome, caused by everything and having consequences for everything, therefore, explaining nothing.

Having set the directions that others should follow allows me to be optimistic for future progress anticipating some younger scholar will solve those conceptual problems. That optimism was shaken recently when the fortune cookie presented to me with my bill at the nearby Vietnamese restaurant, proclaimed that "In youth and beauty, wisdom is rare." While that tempered my optimism, it also provided me with an explanation for my own failures. 